\title{
EVALUATION OF OCCUPATIONAL PHYSICAL LOAD DURING 6-MONTH INTERNATIONAL CRISIS MANAGEMENT OPERATION
}

\section{KAI PIHLAINEN ${ }^{1}$, MATTI SANTTILA², TOMMI VASANKARI ${ }^{3}$, KEIJO HÄKKINEN ${ }^{4}$, and HEIKKI KYRÖLÄINEN 2,4}

${ }^{1}$ Finnish Defence Forces, Helsinki, Finland

Training Division of Defence Command

${ }^{2}$ National Defence University, Helsinki, Finland

${ }^{3}$ UKK Institute for Health Promotion Research, Tampere, Finland

${ }^{4}$ University of Jyväskylä, Jyväskylä, Finland

Department of Biology of Physical Activity

\begin{abstract}
Objectives: Generally, operational military duties are associated with a variety of stressors, such as prolonged physical activity (PA). However, limited information is available on the occupational workload or changes in PA during international military operations. Thus, the aim of the study was to investigate the changes in body composition, stress biomarkers, PA, and heart rate (HR) responses of 79 male soldiers during a 6-month international crisis management operation. Material and Methods: Measurements were conducted 3 times in South-Lebanon during the operation. Body composition was assessed by the bioelectrical impedance method. Blood samples were analyzed for serum testosterone, sex-hormone binding globulin (SHBG), cortisol and insulin-like growth factor. Saliva sampling was used for analyzing stress biomarkers, cortisol and $\alpha$-amylase. Heart rate and physical activity were monitored by a recordable belt and tri-axial accelerometer, respectively. Results: Increases in muscle mass $(39.2 \pm 4.1 \mathrm{vs} .39 .5 \pm 4.2 \mathrm{~kg}$, $\mathrm{p}<0.05)$ and testosterone $(15.9 \pm 4.6$ vs. $17.2 \pm 4 \mathrm{nmol} / \mathrm{l}, \mathrm{p}<0.01)$, and reductions in PA variables (e.g., daily step count $9472 \pm 2547$ vs. $8321 \pm 2720$, p < 0.05) were observed during the first half (i.e., PRE-MID) of the study. The increase in muscle mass remained significant during the latter half (PRE-POST, $39.2 \pm 4.1 \mathrm{vs.} 39.6 \pm 4.4 \mathrm{~kg}, \mathrm{p}<0.05$ ), but also fat mass increased (MID-POST, $10.6 \pm 4.6$ vs. $11.0 \pm 4.7 \mathrm{~kg}, \mathrm{p}<0.05$ ) while SHBG (MID-POST, $31.8 \pm 12.1 \mathrm{vs.} 26.6 \pm 13.2 \mathrm{nmol} / \mathrm{l}$, $\mathrm{p}<0.01$ ) and cortisol (MID-POST, $445 \pm 116$ vs. $400 \pm 123 \mathrm{nmol} / \mathrm{l}, \mathrm{p}<0.05$ ) decreased. With the exception of increased concentration of salivary $\alpha$-amylase (PRE-POST, $36.5 \pm 33.7$ vs. $55.1 \pm 39.7 \mathrm{U} / \mathrm{ml}$ ), the acute stress biomarkers and HR responses remained unchanged. Furthermore, the low quantity of PA, low HR values and subjective ratings of exertion refer to rather light physical workload. Conclusions: Due to the operatively calm nature of the working environment, the present soldiers did not express any significant signs of physical overload during the study period. Int J Occup Med Environ Health 2018;31(2):185-197
\end{abstract}

Key words:

Workload, Military personnel, Physical exertion, Occupational health, Military medicine, Accelerometry

Funding: The Scientific Advisory Board for Defence (Finland) and the National Defence Foundation (Finland).

Received: June 21, 2016. Accepted: January 2, 2017.

Corresponding author: K. Pihlainen, Finnish Defence Forces, Training Division of Defence Command, PO Box 919, 00130 Helsinki, Finland (e-mail: kai.pihlainen@gmail.com). 


\section{INTRODUCTION}

Many of the operational military duties have been characterized as prolonged, low intensity physical activity (PA) intermittent by shorter bouts of higher intensity activities [1,2]. Military tasks are often performed with extra loads and protective equipment such as body armor, which increase the energy expenditure of such activities [1,3-6]. In addition to physical strain, negative energy balance, sustained readiness and sleep deprivation, high ambient temperature, altitude and environmental toxins may all separately or in combination disturb homeostasis of the body and thus, increase stress of soldiers [1,2,7]. Consequently, these stressors may lead to degraded performance and increased risk for illnesses and task or mission failure [2,7]. Internal or external threats in a military environment may lead to acute stress modifying the function of the autonomic nervous system that may be indirectly evaluated by studying metabolic and neuroendocrine responses such as vagal activity of the heart and catabolic (e.g., cortisol) or anabolic biomarkers (e.g., testosterone, insulin-like growth factor-1) [2,8]. An increase in the concentration of catabolic hormones and stressful situations per se may activate immune function [8]. Prolonged stress may weaken the immune function and lead to various diseases or syndromes such as hypertension, atherosclerosis and metabolic syndrome [9].

Acute occupational physical workload may be assessed by several field measurements, such as recording of cardiorespiratory responses [5], analyzing stress biomarkers from blood and saliva samples [2,10-12] as well as quantifying PA by accelerometers [13,14]. In a follow-up of chronic stress development, the same methods may be used during military operations. In addition, changes in body mass or body composition constitute an essential part of the follow-up since many of the deleterious effects of the degraded performance are associated with body weight loss $[1,2,10,11]$. Most of the military studies examining occupational workload have focused on field exercises, while scientific information concerning the physical strain during international military operations seems to be limited.

Therefore, the purpose of this study was to investigate changes in body composition, blood and saliva stress biomarkers, volume and intensity of PA, and heart rate responses during the 6-month crisis management operation in the Middle East.

\section{MATERIAL AND METHODS}

\section{Subjects and ethics}

More than 250 soldiers were deployed for 6 months in the crisis management operation in the Middle East, out of whom 79 male soldiers took voluntarily part in this study. Before the deployment, the soldiers were examined by a physician. They were informed of the study design and gave written consents for their participation. The study was conducted in accordance to the guidelines of the Ethical Committee of the Central Finland Health Care District. All measurements were carried out 3 times, mainly inside the military base in South-Lebanon. The initial measures (PRE) were conducted after a 2-week acclimatization period. The respective measurements were repeated 9 (MID) and 19 (POST) weeks after the initial measures.

\section{Study protocol and conditions}

The soldiers served in a unit with the mission of monitoring the cessation of hostilities and supporting the government of Lebanon as well as the local population. The military base in which the soldiers were mainly accommodated was situated on a hill, $775 \mathrm{~m}$ above the sea-level.

The most typical task for operative soldiers was patrolling for 4- $6 \mathrm{~h}$ /day by vehicles around the area of the operative responsibility. Typical operative duties also consisted in daily guarding of the military base for one to $8 \mathrm{~h}$. Soldiers in the headquarters and logistic units worked mainly inside the base. The operative units worked in 3 shifts 
around the clock, while the logistic units worked mainly during a day-time. However, there were separate individual duties among all personnel groups that required 24-h readiness. The security situation at the operation area remained relatively calm throughout the study period. Nonetheless, the situation was continuously susceptible to rapid changes causing soldiers to conduct their daily duties in a peaceful environment while simultaneously being forced to remain vigilant of different types of threats.

The average ambient temperature, recorded in one-hour intervals throughout the 6-month study period (Thermochron iButton, Maxim Integrated, San Jose, California, USA) inside the military camp was $22.3 \pm 4.3^{\circ} \mathrm{C}$ (range: $\left.11-36^{\circ} \mathrm{C}\right)$. The soldiers had air-conditioning in their accommodation, and no heat illnesses were reported during the study period.

\section{Measurements}

Body composition measurements and blood sampling were conducted in the morning after an overnight fast at a military hospital. Body height was measured to the nearest $0.1 \mathrm{~cm}$ by using a wall-mounted height board (Seca Bodymeter 206, Seca, Hamburg, Germany). Body mass (BM), skeletal muscle mass (SMM), fat mass (FATM) were determined to the nearest $0.1 \mathrm{~kg}$ by using the segmental multi-frequency bioimpedance analysis assessment (InBody 720, Biospace, Seoul, South Korea) in accordance with the manufacturer's guidelines.

Blood samples were drawn from the antecubital vein. Plasma and serum were separated from blood by using a centrifuge $(1000 \mathrm{rpm}, 8 \mathrm{~min})$ and frozen below $-20^{\circ} \mathrm{C}$ for the purpose of further transportation and analysis. Assays for serum testosterone (TES), sex-hormone binding globulin (SHBG), cortisol (COR) and insulin-like growth factor-1 (IGF1) were performed by Immulite 2000 XPi (Siemens Healthcare, Llanberies, UK) using commercial chemiluminescent enzyme immunoassay kits according to the manufacturer's guidelines.
The inter-assay coefficients of variance (CV) for assays of TES, SHBG, COR and IGF-I were 7-7.2, 4.5-6.2, 4.6-5.8 and 3.7-7.4\%, and that of sensitivity $0.5,0.02$, $5.5 \mathrm{nmol} / \mathrm{l}$ and $2.6 \mathrm{pmol} / \mathrm{l}$, respectively.

The workload assessment was conducted by using heart rate (HR) recording, saliva sampling, and accelerometer to measure PA. The measurement methods were guided to the soldiers in advance at the military base but implemented during their duties in an operational environment.

Heart rate (HR) was recorded up to 3 days by a recordable memory belt (Memory belt, Suunto, Vantaa, Finland). Individual absolute and relative mean HR were analyzed for a 24-h period by a computer analysis software (Firsbeat PRO, Firstbeat Technologies, Jyväskylä, Finland). Physical activity was recorded by a tri-axial accelerometer at a frequency of $100 \mathrm{~Hz}$ (Hookie AM20, Traxmeet, Espoo, Finland). The device was positioned to the left side of the trunk at the height of the hip with an elastic band. The soldiers were instructed to wear the accelerometer for 10 days at all times with the exception of sleeping and water activities (e.g., shower). Minimum requirement for the inclusion of accelerometer data for further analyses was 4 days with at least $10 \mathrm{~h}$ of wearing time each day. The accelerometer data was analyzed for metabolic equivalent (MET) intensities and step counts by using a mean amplitude deviation according to the previously published validation [15].

Saliva samples with concurrent ratings of perceived exertion (RPE) [16] were collected 6 times during one typical working day by using cotton swabs according to the manufacturer's guidelines (Salivette, Sarstedt, Nümbrecht, Germany). The saliva samples and RPE were instructed to be self-collected after a normal night's sleep, immediately at the time of wake-up followed by $30 \mathrm{~min}, 1 \mathrm{~h}, 4 \mathrm{~h}$ and $10 \mathrm{~h}$ after wake-up. The last sample was collected just before going to bed for a night-time sleep. With the exception of the first sample the soldiers were instructed to rinse 
their mouth with water 10 min prior to sampling. The soldiers were also informed to keep the sealed sample containers in a dry and, if possible, cool place during their duties. The samples had been delivered to the military base hospital on the following morning of sampling and stored at $-20^{\circ} \mathrm{C}$ until they were transported in a frozen state for the purpose of further analysis. The samples were thawed and centrifuged at $3500 \mathrm{rpm}$ for $10 \mathrm{~min}$. Saliva cortisol (saCOR) and $\alpha$-amylase (saAA), as potential determinants of stress [17,18], were analyzed.

Saliva cortisol was analyzed by Immulite 2000 XPi (Siemens Healthcare, UK) using chemiluminescent enzyme immunoassay kits, while saAA assays were performed by Konelab 20XTi (Thermo Fisher Scientific, Vantaa, Finland) using the enzyme photometric measurement method (inter-assay CV $13.2 \%$ and $3.2 \%$, respectively). Daily mean values from all ratings (RPE) and samples (saCOR, saAA) were formed for the purpose of further statistical analyses.

Peak HR $\left(\mathrm{HR}_{\text {peak }}\right)$ was determined during a 3000-m running test inside the military base. The subjects were instructed to complete the test with a maximal effort and in the shortest possible time. Heart rate was continuously recorded by using the recordable memory belt (Memory Belt, Suunto, Vantaa, Finland). Peak heart rate was determined by the computer analysis software (Firsbeat PRO,
Firstbeat Technologies, Jyväskylä, Finland) as the highest recorded HR during the running test.

\section{Statistics}

Commercial software (IBM SPSS 22.0.0, Chicago, USA) was used for the purpose of the statistical analyses. Data was analyzed by using repeated-measures ANOVA and t-tests when appropriate. If the model was statistically significant, pairwise group and time comparisons were performed. If assumptions were not to meet logarithm, transformations were applied, or finally nonparametric tests utilized. The relationships among relative changes of the measured variables were tested for linearity with Spearman's product moment correlation coefficients. The $\mathrm{p}<0.05$ was used for establishing statistical significance.

Soldiers were divided into 2 groups according to their tasks for group-wise comparison. The soldiers in the operative infantry units formed group A ( $\mathrm{N}=41)$ while headquarters and logistic units formed group $\mathrm{B}(\mathrm{N}=38)$. Due to the demands of high readiness, the present soldiers were not able to attend all the measurements. Therefore, a maximum number of soldiers who took part in all PRE-, MIDand POST-measurements were used in statistical analyses for each variable, and the results are also presented for the total subject group (i.e., group A+B). Physical characteristics of the soldiers are presented in the Table 1.

Table 1. Physical characteristics of male soldiers taking part in the 6-month international crisis management operation

\begin{tabular}{|c|c|c|c|}
\hline \multirow[b]{2}{*}{ Variable } & \multicolumn{3}{|c|}{ Study group } \\
\hline & $\begin{array}{c}\text { total } \\
(\mathrm{N}=79)\end{array}$ & $\begin{array}{c}\mathrm{A} \\
\text { (operative infantry units) } \\
(\mathrm{N}=41)\end{array}$ & $\begin{array}{c}\text { B } \\
\text { (headquarters } \\
\text { and logistic units) } \\
(\mathrm{N}=38)\end{array}$ \\
\hline Age [years] $(\mathrm{M} \pm \mathrm{SD})$ & $29.8 \pm 8.0$ & $26.4 \pm 5.6$ & $34.1 \pm 8.6$ \\
\hline Body height $[\mathrm{cm}](\mathrm{M} \pm \mathrm{SD})$ & $179.1 \pm 7.4$ & $180.0 \pm 7.8$ & $178.0 \pm 6.7$ \\
\hline Body mass $[\mathrm{kg}](\mathrm{M} \pm \mathrm{SD})$ & $79.4 \pm 8.1$ & $79.1 \pm 7.1$ & $79.9 \pm 9.2$ \\
\hline Body mass index $\left[\mathrm{kg} / \mathrm{m}^{2}\right](\mathrm{M} \pm \mathrm{SD})$ & $24.5 \pm 2.4$ & $24.0 \pm 1.9$ & $25.1 \pm 2.7$ \\
\hline
\end{tabular}

$\mathrm{M}$ - mean; SD - standard deviation. 


\section{RESULTS}

\section{Body composition and blood biomarkers}

Body mass remained unchanged during the first half of the study period (from PRE-MID), while significant increases were observed during the latter part (from MID-POST) in the total subject group $(\mathrm{A}+\mathrm{B}, 1 \pm 2 \%, \mathrm{p}<0.01)$ and in the group $\mathrm{A}(1 \pm 2 \%, \mathrm{p}<0.05)$. Skeletal muscle mass increased from PRE-MID by $1 \pm 3 \%$ in the total subject group $(p<0.05)$, while the increases from PRE-POST were significant in all groups (Table 2). The group B reduced FATM from PRE-MID $(-4 \pm 24 \%, \mathrm{p}<0.05)$ and regained it from MID-POST $(6 \pm 14 \%, \mathrm{p}<0.05)$. No differences between the groups were observed in BM and SMM during the study while FATM was higher in the group B in all comparison points. Individual increases in SMM were associated with individual decreases in SHBG $(\mathrm{r}=-0.33, \mathrm{p}<0.05, \mathrm{~N}=60)$ as well as saAA $(\mathrm{r}=-0.39, \mathrm{p}<0.05, \mathrm{~N}=41)$ from MID-POST.
Serum TES concentrations increased from PRE-MID in the total subject group $(13 \pm 31 \%, \mathrm{p}<0.01)$ and the group A $(12 \pm 24 \%, \mathrm{p}<0.01)$ (Table 2). In contrast, SHGB decreased in both groups from MID-POST (group $\mathrm{A} ;-18 \pm 34 \%, \mathrm{p}<0.01$, group $\mathrm{B} ;-9 \pm 22 \%$, $\mathrm{p}<0.05$ ) as well as from PRE-POST (group A; $-19 \pm 35 \%$, $\mathrm{p}<0.05$, group $\mathrm{B} ;-14 \pm 24 \%, \mathrm{p}<0.01)$. Cortisol decreased significantly from MID-POST in the total subject group $(-5 \pm 33 \%, \mathrm{p}<0.05)$ and the group A $(-14 \pm 38 \%$, $\mathrm{p}<0.01)$. These changes led to significant increases in the TES-to-SHBG ratio (TES/SHBG) from PRE-POST as well as from MID-POST in all groups. The TES-toCOR ratio (TES/COR) increased accordingly, but only in the total subject group and in group A. A significant group difference was observed in the TES/SHBG $(p<0.05)$ and TES/COR ratios $(\mathrm{p}<0.01)$ during POST. No changes in IGF1 were observed during the study in either group. However, the group A showed higher IGF1 con-

Table 2. Male soldiers' body composition and serum biomarkers in the beginning (PRE), middle (MID) and at the end (POST) of the 6-month international crisis management operation

\begin{tabular}{|c|c|c|c|}
\hline Variable & PRE & MID & POST \\
\hline \multicolumn{4}{|l|}{ Body mass $[\mathrm{kg}](\mathrm{M} \pm \mathrm{SD})$} \\
\hline total group $(\mathrm{N}=79)$ & $79.40 \pm 8.10$ & $79.30 \pm 8.20$ & $79.90 \pm 8.80^{* * * *}$ \\
\hline group $\mathrm{A}(\mathrm{N}=41)$ & $79.10 \pm 7.10$ & $79.10 \pm 7.20$ & $79.60 \pm 7.60^{* *}$ \\
\hline group $\mathrm{B}(\mathrm{N}=38)$ & $79.90 \pm 9.20$ & $79.60 \pm 9.30$ & $80.10 \pm 10.00$ \\
\hline \multicolumn{4}{|c|}{ Skeletal muscle mass $(\mathrm{SMM})[\mathrm{kg}](\mathrm{M} \pm \mathrm{SD})$} \\
\hline total group $(\mathrm{N}=79)$ & $39.20 \pm 4.10$ & $39.50 \pm 4.20^{*}$ & $39.60 \pm 4.40^{*}$ \\
\hline $\operatorname{group} \mathrm{A}(\mathrm{N}=41)$ & $39.80 \pm 4.00$ & $40.00 \pm 4.10$ & $40.10 \pm 4.30^{*}$ \\
\hline group $\mathrm{B}(\mathrm{N}=38)$ & $38.60 \pm 4.20$ & $38.80 \pm 4.30$ & $39.00 \pm 4.50^{*}$ \\
\hline \multicolumn{4}{|l|}{ Fat mass $(\mathrm{FATM})[\mathrm{kg}](\mathrm{M} \pm \mathrm{SD})$} \\
\hline total group $(\mathrm{N}=79)$ & $11.00 \pm 4.80$ & $10.60 \pm 4.60$ & $11.00 \pm 4.70^{* *}$ \\
\hline $\operatorname{group} \mathrm{A}(\mathrm{N}=41)$ & $9.70 \pm 3.70$ & $9.50 \pm 3.70$ & $9.90 \pm 3.70$ \\
\hline group $\mathrm{B}(\mathrm{N}=38)$ & $12.40 \pm 5.50^{\#}$ & $11.70 \pm 5.20^{*, \#}$ & $12.20 \pm 5.40^{* *, \#}$ \\
\hline \multicolumn{4}{|l|}{ Testosterone (TES) $[\mathrm{nmol} / 1](\mathrm{M} \pm \mathrm{SD})$} \\
\hline total group $(\mathrm{N}=59)^{\mathrm{a}}$ & $15.90 \pm 4.60$ & $17.2 \pm 4.00^{*}$ & $17.30 \pm 3.60$ \\
\hline $\operatorname{group} A(\mathrm{~N}=29)$ & $16.30 \pm 5.40$ & $18.0 \pm 4.10^{*}$ & $17.90 \pm 3.50$ \\
\hline group $\mathrm{B}(\mathrm{N}=30)$ & $15.50 \pm 3.80$ & $16.5 \pm 3.90$ & $16.80 \pm 3.80$ \\
\hline
\end{tabular}


Table 2. Male soldiers' body composition and serum biomarkers in the beginning (PRE), middle (MID) and at the end (POST) of the 6-month international crisis management operation - cont.

\begin{tabular}{|c|c|c|c|}
\hline Variable & PRE & MID & POST \\
\hline \multicolumn{4}{|c|}{ Sex-hormone binding globulin (SHBG) [nmol/l] $(\mathrm{M} \pm \mathrm{SD})$} \\
\hline total group $(\mathrm{N}=59)^{\mathrm{a}}$ & $32.30 \pm 12.00$ & $31.80 \pm 12.10$ & $26.60 \pm 13.20^{*, * *}$ \\
\hline group A $(\mathrm{N}=29)$ & $31.00 \pm 13.40$ & $32.40 \pm 15.70$ & $25.50 \pm 16.40^{*, * *}$ \\
\hline group $\mathrm{B}(\mathrm{N}=30)$ & $33.60 \pm 10.50$ & $31.20 \pm 7.50$ & $27.70 \pm 9.30^{*, * *}$ \\
\hline \multicolumn{4}{|c|}{$\begin{array}{l}\text { Testosterone to sex-hormone binding globulin ratio } \\
(\mathrm{TES} / \mathrm{SHBG})[\mathrm{nmol} / \mathrm{l}](\mathrm{M} \pm \mathrm{SD})\end{array}$} \\
\hline total group $(\mathrm{N}=59)^{\mathrm{a}}$ & $0.54 \pm .020$ & $0.60 \pm 0.21$ & $0.80 \pm 0.43^{*, * *}$ \\
\hline group $A(N=29)$ & $0.58 \pm .021$ & $0.64 \pm 0.25$ & $0.95 \pm 0.55^{*, * *}$ \\
\hline group $\mathrm{B}(\mathrm{N}=30)$ & $0.50 \pm .019$ & $0.55 \pm 0.16$ & $0.65 \pm 0.18^{*, * *, \#}$ \\
\hline \multicolumn{4}{|c|}{ Insulin-like growth factor $1(\mathrm{IGF} 1)[\mathrm{pmol} / \mathrm{l}](\mathrm{M} \pm \mathrm{SD})$} \\
\hline total group $(\mathrm{N}=59)^{\mathrm{a}}$ & $27.40 \pm 9.90$ & $27.60 \pm 10.20$ & $25.90 \pm 9.80$ \\
\hline group A $(\mathrm{N}=29)$ & $31.90 \pm 9.20$ & $33.00 \pm 9.00$ & $28.80 \pm 10.80$ \\
\hline group $\mathrm{B}(\mathrm{N}=30)$ & $23.00 \pm 8.50^{\#}$ & $22.30 \pm 8.60^{\#}$ & $23.10 \pm 7.90^{\#}$ \\
\hline \multicolumn{4}{|l|}{ Cortisol (COR) $[\mathrm{nmol} / \mathrm{l}](\mathrm{M} \pm \mathrm{SD})$} \\
\hline total group $(\mathrm{N}=59)^{\mathrm{a}}$ & $425.00 \pm 101.00$ & $445.00 \pm 116.00$ & $400.00 \pm 123.00^{* *}$ \\
\hline group $A(N=29)$ & $420.00 \pm 108.00$ & $476.00 \pm 127.00$ & $368.00 \pm 138.00^{* *}$ \\
\hline group $\mathrm{B}(\mathrm{N}=30)$ & $429.00 \pm 96.00$ & $414.00 \pm 98.00$ & $430.00 \pm 99.00^{\#}$ \\
\hline \multicolumn{4}{|c|}{ Testosterone to cortisol ratio (TES/COR) $[\mathrm{nmol} / \mathrm{l}](\mathrm{M} \pm \mathrm{SD})$} \\
\hline total group $(\mathrm{N}=59)^{\mathrm{a}}$ & $0.04 \pm 0.02$ & $0.04 \pm 0.01$ & $0.05 \pm 0.02^{*, * *}$ \\
\hline group A $(\mathrm{N}=29)$ & $0.04 \pm 0.02$ & $0.04 \pm 0.01$ & $0.05 \pm 0.02^{* * * *}$ \\
\hline group $B(N=30)$ & $0.04 \pm 0.01$ & $0.04 \pm 0.01$ & $0.04 \pm 0.01^{\#}$ \\
\hline
\end{tabular}

Group A - operative infantry units; group B - headquarters and logistic units.

${ }^{\text {a }}$ Due to the demands of high readiness, the soldiers $(\mathrm{N}=79)$ were not able to attend all the measurements. Therefore, a maximum number of soldiers who took part in all PRE-, MID- and POST-measurements were used in statistical analyses for each variable.

* Within-group comparison: significantly different from PRE $(\mathrm{p}<0.05)$.

** Within-group comparison: significantly different from MID $(\mathrm{p}<0.05)$.

${ }^{\#}$ Between-group comparison: significantly different from group A $(\mathrm{p}<0.05)$.

Other abbreviations as in Table 1.

centrations at all time points as well as lower COR at POST $(\mathrm{p}<0.05)$.

\section{Workload assessment}

The 24-h HR $\left(\mathrm{HR}^{24 h}\right)$ responses of soldiers are presented in the Table 3. No changes within the groups were found in mean, minimum or peak $\mathrm{HR}^{24 \mathrm{~h}}$ in relation to time. However, relative $H R$ decreased in the total subject group $(A+B)$ from PRE-MID $(-2 \pm 8 \%, \mathrm{p}<0.05)$. The only difference between the groups was the higher mean $\mathrm{HR}^{24 \mathrm{~h}}$ in the group $\mathrm{A}$ as compared to B during POST ( $p<0.05)$. Individual increases in mean $\mathrm{HR}^{24 \mathrm{~h}}$ were associated with individual decreases in IGF1 ( $\mathrm{r}=-0.46, \mathrm{p}<0.05, \mathrm{~N}=25)$ from PRE-MID.

No significant changes were observed in saCOR concentration. However, saAA increased from PRE-POST in the total subject group $(108 \pm 203 \%, \mathrm{p}<0.05)$ as well as in the groups A $(116 \pm 189 \%, \mathrm{p}<0.05)$ and B $(103 \pm 217 \%$, $\mathrm{p}<0.05)$. While no differences were observed between 
Table 3. Male soldiers' 24-h mean heart rate (HR) responses and saliva stress biomarkers in the beginning (PRE), middle (MID) and at the end (POST) of the 6-month international crisis management operation

\begin{tabular}{|c|c|c|c|}
\hline Variable & PRE & MID & POST \\
\hline \multicolumn{4}{|l|}{$\mathrm{HR}_{\text {mean }}^{24 \mathrm{~h}}[\mathrm{bpm}](\mathrm{M} \pm \mathrm{SD})$} \\
\hline total group $(\mathrm{N}=26)^{\mathrm{a}}$ & $72 \pm 6$ & $70 \pm 7$ & $71 \pm 8$ \\
\hline group $\mathrm{A}(\mathrm{N}=15)$ & $70 \pm 6$ & $70 \pm 8$ & $71 \pm 10$ \\
\hline group $\mathrm{B}(\mathrm{N}=11)$ & $73 \pm 7$ & $69 \pm 6$ & $71 \pm 7$ \\
\hline \multicolumn{4}{|l|}{$\mathrm{HR}_{\min }{ }^{24 \mathrm{~h}}[\mathrm{bpm}](\mathrm{M} \pm \mathrm{SD})$} \\
\hline total group $(\mathrm{N}=26)^{\mathrm{a}}$ & $47 \pm 5$ & $46 \pm 5$ & $47 \pm 5$ \\
\hline group $A(N=15)$ & $47 \pm 6$ & $47 \pm 5$ & $48 \pm 6$ \\
\hline group $B(N=11)$ & $46 \pm 3$ & $46 \pm 5$ & $46 \pm 5$ \\
\hline \multicolumn{4}{|l|}{$\mathrm{HR}_{\text {peak }}^{24 \mathrm{~h}}[\mathrm{bpm}](\mathrm{M} \pm \mathrm{SD})$} \\
\hline total group $(\mathrm{N}=26)^{\mathrm{a}}$ & $147 \pm 18$ & $139 \pm 21$ & $148 \pm 19$ \\
\hline group $A(N=15)$ & $145 \pm 15$ & $141 \pm 27$ & $140 \pm 19$ \\
\hline group $\mathrm{B}(\mathrm{N}=11)$ & $149 \pm 20$ & $138 \pm 17$ & $153 \pm 18^{\#}$ \\
\hline \multicolumn{4}{|l|}{$\mathrm{HR}^{24 \mathrm{~h}}\left[\% \mathrm{HR}_{\text {peak }}\right](\mathrm{M} \pm \mathrm{SD})$} \\
\hline total group $(\mathrm{N}=26)^{\mathrm{a}}$ & $37.6 \pm 3.8$ & $36.5 \pm 3.9^{*}$ & $37.2 \pm 4.6$ \\
\hline group $A(N=15)$ & $36.1 \pm 3.2$ & $36.1 \pm 4.7$ & $36.7 \pm 5.4$ \\
\hline group $\mathrm{B}(\mathrm{N}=11)$ & $38.7 \pm 3.9$ & $36.7 \pm 3.5$ & $37.5 \pm 4.0$ \\
\hline \multicolumn{4}{|c|}{ Saliva cortisol (saCOR) [nmol/1] (M \pm SD) } \\
\hline total group $(\mathrm{N}=34)^{\mathrm{a}}$ & $14.2 \pm 5.4$ & $15.0 \pm 6.3$ & $17.4 \pm 7.1$ \\
\hline group $A(N=14)$ & $11.1 \pm 2.7$ & $13.2 \pm 3.5$ & $13.8 \pm 7.7$ \\
\hline group $\mathrm{B}(\mathrm{N}=20)$ & $16.4 \pm 5.7$ & $16.3 \pm 7.5$ & $19.9 \pm 5.4^{\#}$ \\
\hline \multicolumn{4}{|c|}{ Saliva $\alpha$-amylase (saAA) $[\mathrm{U} / \mathrm{ml}](\mathrm{M} \pm \mathrm{SD})$} \\
\hline total group $(\mathrm{N}=39)^{\mathrm{a}}$ & $36.5 \pm 33.7$ & $49.1 \pm 35.3$ & $55.1 \pm 39.7^{*}$ \\
\hline group A $(\mathrm{N}=16)$ & $34.9 \pm 24.0$ & $52.5 \pm 49.5$ & $55.5 \pm 45.1^{*}$ \\
\hline group $B(N=23)$ & $41.1 \pm 41.0$ & $46.8 \pm 21.8$ & $54.9 \pm 36.5^{*}$ \\
\hline
\end{tabular}

Explanations as in Table 2.

the groups in saAA during the study, saCOR concentration was higher in the group $\mathrm{B}(\mathrm{p}<0.05)$ during POST (Table 3). A positive correlation in the individual changes between saCOR and SHBG $(\mathrm{r}=0.30, \mathrm{p}<0.05, \mathrm{~N}=43)$, as well as saAA and mean $\mathrm{HR}^{24 \mathrm{~h}}(\mathrm{r}=0.37, \mathrm{p}<0.05$, $\mathrm{N}=41$ ) were observed from PRE-POST.

The daily mean RPE of soldiers (group $\mathrm{A}+\mathrm{B}, \mathrm{N}=24$ ) remained unchanged $(9 \pm 1)$ throughout the study and no within- or between-group differences were found.
A positive correlation was observed in the MID-POST individual changes between RPE and COR ( $\mathrm{r}=0.41$, $\mathrm{p}<0.05, \mathrm{~N}=25$ ).

\section{Physical activity}

The accelerometer data was collected for $9.3 \pm 2.5$, $9.6 \pm 3.1$ and $9.6 \pm 2.8$ days during PRE, MID and POST, respectively. The respective daily wearing times of the accelerometer were 14:27 \pm 1:39 h:min, 13:45 $\pm 1: 40$ h:min 
and 14:13 $\pm 1: 47 \mathrm{~h}: \mathrm{min}$. In relative terms, the total subject group $(\mathrm{A}+\mathrm{B})$ spent $76 \pm 6 \%$ of wearing time at a level of sedentary behavior (MET < 1.5) during PRE (Table 4). The relative volume of sedentary time increased by $2 \pm 6 \%$ in the total subject group and by $3 \pm 6 \%$ in the group B from PRE-POST ( $p<0.05)$. However, in absolute terms (h:min), the increased sedentary time was observed in the total subject group $(A+B, 5 \pm 12 \%, p<0.05)$ and the group A $(4 \pm 9 \%, \mathrm{p}<0.05)$ from MID-POST.

A significant reduction in the absolute volume of light PA (MET $=1.5-3)$ was observed only in group B $(-12 \pm 29 \%)$ from PRE-MID $(p<0.05)$. Concurrent reductions in absolute and relative volumes of moderate PA (MET = 3-6) were observed in the total sub- ject group and the group B (Table 4). Nonetheless, the group $\mathrm{B}$ was generally more active than group $\mathrm{A}$ in all PA levels.

The daily step count of soldiers $(\mathrm{A}+\mathrm{B})$ decreased from the initial levels by $-10 \pm 24 \%$ ( $9472 \pm 2547$ vs. $8321 \pm 2720$, $\mathrm{p}<0.05)$ from PRE-MID and by $-7 \pm 29 \%(9472 \pm 2547$ vs. $8517 \pm 2772, \mathrm{p}<0.05)$ from PRE-POST. In the group level, a significant reduction was observed in the group B $(-12 \pm 25 \%, 10594 \pm 2122$ vs. $9288 \pm 3133, p<0.05)$ from PRE-POST. Again, the PA of group B was significantly higher during PRE (10 594 \pm 2122 vs. 8291 $\pm 2460, p<0.01$ ) and MID $(9515 \pm 2985$ vs. $7065 \pm 1720, \mathrm{p}<0.01)$ as compared to group A (Figure 1). The changes in running steps were non-significant in all comparisons (Figure 2). High

Table 4. Male soldiers' mean absolute and relative volume of physical activity in different metabolic equivalent (MET) intensities in the beginning (PRE), middle (MID) and at the end (POST) of the 6-month international crisis management operation

\begin{tabular}{|c|c|c|c|c|c|c|}
\hline \multirow[b]{2}{*}{ Variable } & \multicolumn{2}{|c|}{ PRE } & \multicolumn{2}{|c|}{ MID } & \multicolumn{2}{|c|}{ POST } \\
\hline & $\begin{array}{c}\text { absolute } \\
\text { [h:min] } \\
(\mathrm{M} \pm \mathrm{SD})\end{array}$ & $\begin{array}{c}\text { relative }^{\mathrm{b}} \\
{[\%]} \\
(\mathrm{M} \pm \mathrm{SD})\end{array}$ & $\begin{array}{c}\text { absolute } \\
\text { [h:min] } \\
(\mathrm{M} \pm \mathrm{SD})\end{array}$ & $\begin{array}{c}\text { relative }^{\mathrm{b}} \\
{[\%]} \\
(\mathrm{M} \pm \mathrm{SD})\end{array}$ & $\begin{array}{c}\text { absolute } \\
\text { [h:min] } \\
(\mathrm{M} \pm \mathrm{SD})\end{array}$ & $\begin{array}{c}\text { relative }^{\mathrm{b}} \\
{[\%]} \\
(\mathrm{M} \pm \mathrm{SD})\end{array}$ \\
\hline \multicolumn{7}{|l|}{$\mathrm{MET}<1.5$} \\
\hline total group $(\mathrm{N}=39)^{\mathrm{a}}$ & $11: 04 \pm 1: 44$ & $76 \pm 6$ & $10: 41 \pm 1: 41$ & $78 \pm 5$ & $11: 08 \pm 1: 42^{* *}$ & $78 \pm 5^{*}$ \\
\hline group $A(N=19)$ & $10: 58 \pm 1: 32$ & $78 \pm 5$ & $10: 46 \pm 1: 29$ & $79 \pm 5$ & $11: 13 \pm 1: 44^{* *}$ & $79 \pm 5$ \\
\hline group $B(N=20)$ & $11: 10 \pm 1: 57$ & $75 \pm 6$ & $10: 37 \pm 1: 53$ & $77 \pm 6$ & $11: 03 \pm 1: 42$ & $77 \pm 5^{*}$ \\
\hline \multicolumn{7}{|l|}{ MET $1.5-3.0$} \\
\hline total group $(\mathrm{N}=39)^{\mathrm{a}}$ & $1: 45 \pm 0: 26$ & $12 \pm 3$ & $1: 38 \pm 0: 22$ & $12 \pm 3$ & $1: 39 \pm 0: 25$ & $12 \pm 3$ \\
\hline group $A(N=19)$ & $1: 35 \pm 0: 20$ & $11 \pm 3$ & $1: 37 \pm 0: 18$ & $12 \pm 2$ & $1: 33 \pm 0: 22$ & $11 \pm 3$ \\
\hline group $\mathrm{B}(\mathrm{N}=20)$ & $1: 55 \pm 0: 26^{\#}$ & $13 \pm 3$ & $1: 38 \pm 0: 26^{*}$ & $12 \pm 3$ & $1: 45 \pm 0: 27$ & $12 \pm 3$ \\
\hline \multicolumn{7}{|l|}{ MET 3.0-6.0 } \\
\hline total group $(\mathrm{N}=39)^{\mathrm{a}}$ & $1: 27 \pm 0: 23$ & $10 \pm 3$ & $1: 17 \pm 0: 21^{*}$ & $9 \pm 3^{*}$ & $1: 16 \pm 0: 22 *$ & $9 \pm 2^{*}$ \\
\hline group $A(N=19)$ & $1: 17 \pm 0: 19$ & $9 \pm 2$ & $1: 10 \pm 0: 15$ & $9 \pm 2$ & $1: 11 \pm 0: 16$ & $9 \pm 2$ \\
\hline group $B(N=20)$ & $1: 36 \pm 0: 24^{\#}$ & $11 \pm 3$ & $1: 24 \pm 0: 24^{*}$ & $10 \pm 3^{\#}$ & $1: 21 \pm 0: 26^{*}$ & $9 \pm 3^{*, * *}$ \\
\hline \multicolumn{7}{|l|}{ MET $>6.0$} \\
\hline total group $(\mathrm{N}=39)^{\mathrm{a}}$ & 0:10 $\pm 0: 09$ & $1 \pm 1$ & 0:09 $\pm 0: 08$ & $1 \pm 1$ & $0: 10 \pm 0: 09$ & $1 \pm 1$ \\
\hline group $A(N=19)$ & 0:09 $\pm 0: 09$ & $1 \pm 1$ & $0: 07 \pm 0: 05$ & $1 \pm 1$ & $0: 08 \pm 0: 08$ & $1 \pm 1$ \\
\hline group $B(N=20)$ & 0:12 $\pm 0: 09$ & $1 \pm 1$ & 0:11 $\pm 0: 09$ & $1 \pm 1$ & $0: 12 \pm 0: 09$ & $1 \pm 1$ \\
\hline
\end{tabular}

${ }^{\mathrm{b}}$ Presented as \% of accelerometer wearing time.

Other explanations as in Table 2. 


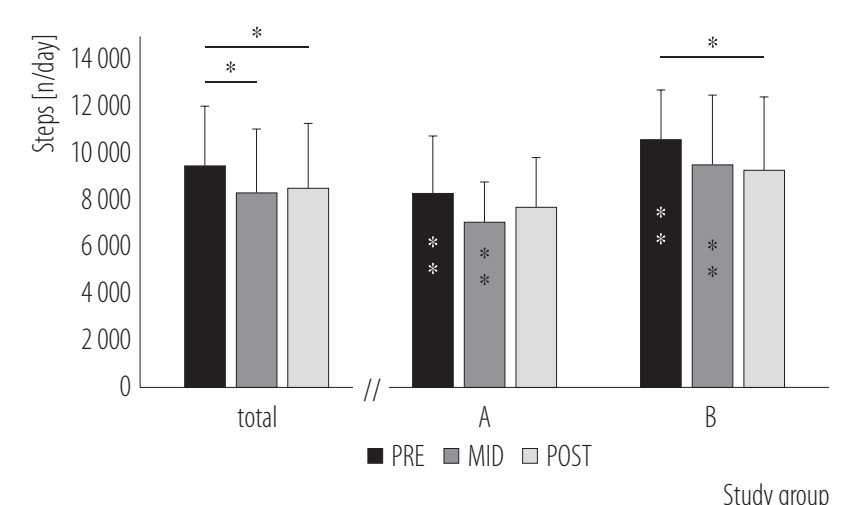

Respondents: total group ( $\mathrm{N}=39)$, group $\mathrm{A}$ - operative infantry units $(\mathrm{N}=19)$, group $\mathrm{B}$ - headquarters and logistic units $(\mathrm{N}=20)$. Within-group comparison: marked with horizontal line ( ${ }^{*} \mathrm{p}<0.05$, $* * \mathrm{p}<0.01)$.

Between-group A and B comparison: marked inside the bars $\left({ }^{*} \mathrm{p}<0.05,{ }^{* *} \mathrm{p}<0.01\right)$.

Fig. 1. Male soldiers' volume of physical activity in daily step count in the beginning (PRE), middle (MID) and at the end (POST) of the 6-month international crisis management operation

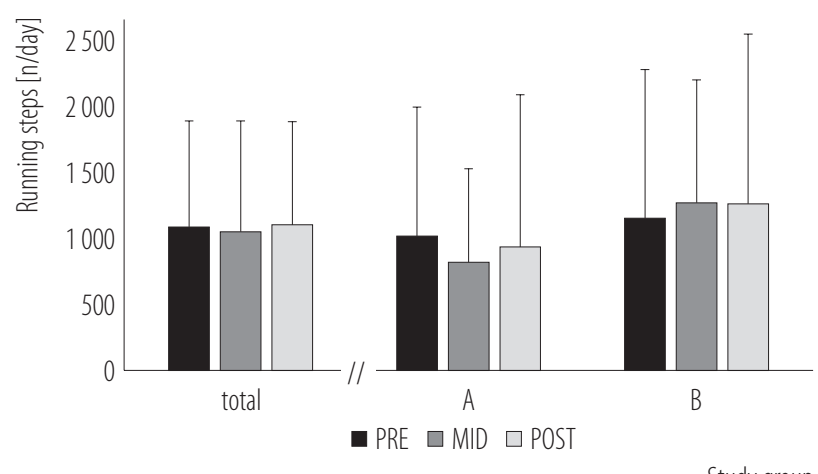

Explanations as in Figure 1.

Fig. 2. Male soldiers' volume of physical activity in daily running step count in the beginning (PRE), middle (MID) and at the end (POST) of the 6-month international crisis management operation

inter-individual differences were observed in PA, as an example, the daily steps ranged between 3345 and 15239 (running steps 18-5541) during the study.

Individual increase in the percentage share of time spent on moderate PA (MET = 3-6) from MID-POST was associated with simultaneous individual increase in BM $(\mathrm{r}=0.53, \mathrm{p}<0.001, \mathrm{~N}=41), \operatorname{SMM}(\mathrm{r}=0.42, \mathrm{p}<0.01$, $\mathrm{N}=41)$, and decrease in TES $(\mathrm{r}=-0.35, \mathrm{p}<0.05, \mathrm{~N}=35)$. In the PRE-POST comparison, associations were found between individual changes in $\mathrm{BM}$ and the percentage share of time spent on MET $<1.5(\mathrm{r}=-0.28, \mathrm{p}<0.05, \mathrm{~N}=60)$, the percentage share of time spent on MET $=1.5-3$ ( $r=0.26, p<0.05, \mathrm{~N}=60$ ), and the percentage share of time spent on MET $=3-6(\mathrm{r}=0.27, \mathrm{p}<0.05, \mathrm{~N}=60)$.

\section{DISCUSSION}

This study has demonstrated that soldiers either in the operative (group A) or in headquarter and logistic staff (group B) duties did not express symptoms of physical overload in terms of the measured variables. In fact, the occupational physical load of the soldiers was surprisingly low. The average daily PA of soldiers did not even exceed the population-wide activity guidelines (e.g., 10000 steps/ day) $[19,20]$. The measured mean relative HR values ranged between $36.5+3.9$ and $37.5 \pm 3.8 \% \mathrm{HR}_{\text {peak }}$, and RPE values remained at the level of $9 \pm 1$. The mean values (HR, RPE, MET) of this study refer to the light level of PA [21], at the most. Furthermore, the hormonal responses indicated an improved anabolic state. Taken together, the findings lead to a conclusion that the soldiers experienced rather a light physical workload during the study period.

During the study period overall security situation in SouthLebanon remained mainly calm without any hostilities. The nature of military duties in this study differed markedly from previous investigations [1,2,7], and this may partly explain the conflicting results. On the other hand, soldiers are required to maintain a high level of readiness for quickly changing security situations. This highlights the demands of the maintenance of physical performance by independent or guided exercise during the deployment.

The decreases in anabolic biomarkers were consistently found as a response to physical exertion combined with en- 
ergy and sleep deprivation in several studies [2,10,11]. Nindl et al. [10] have shown that the 8-day military field exercise with negative energy balance induce a $50 \%$ decrease in total IGF-1 and TES concentrations. Similar findings have been demonstrated by Friedl et al. [11] in a military field exercise lasting for 8 weeks, where significant decreases in TES and IGF-1 concentrations were accompanied with increases in SHBG and COR. These changes were associated with marked reductions in body mass, and the adaptations were soon compensated, when energy balance was leveled [11]. In this study the average body mass of soldiers increased by $0.5 \mathrm{~kg}$. The overall changes in BM of soldiers were modest and at the end of the study they were largely explained by increases in SMM. No decreases in anabolic biomarkers were observed, in fact, most of the changes in the measured blood biomarkers referred to the improved anabolic state. Therefore, it seems that soldiers were not physically overloaded during the mission, even though they additionally performed some recreational exercises. Furthermore, no significant associations between the individual changes in body composition and serum anabolic hormone concentrations were observed.

Cortisol and $\alpha$-amylase have been suggested to reflect the sympathetic activation of the central nervous system as a consequence of physical or psychological strain [12,17]. The positive correlation between the individual changes in saAA and $\mathrm{HR}^{24 \mathrm{~h}}$ supports these findings. With regard to physical strain, acute increase in cortisol has been observed in workloads exceeding $>60 \%$ maximal oxygen consumption $\left(\mathrm{VO}_{2 \max }\right)$ [22] even though psychological stress may accumulate the stress response during lower intensities [23]. Many studies have shown increases in basal levels of cortisol and $\alpha$-amylase as a response to both acute and chronic stress [2,10,11,24,25].

Taverniers and de Boeck [26] have found a correlation between subjective distress and saAA as well as significant increases in saAA during a handgun practice in a simulated real-world environment with a sensation of probable threat by an opponent when compared to training with traditional card-board target.

In this study saCOR remained unaltered but saAA increased from PRE-POST in the both groups. It was obvious that the increase in saAA was more affected by psychological distress than physical overload. Furthermore, conflicting results from previous studies $[27,28]$ complicate inference and highlight the importance of further studies on saAA alterations for humans suffering from chronic stress. Also, Thoma et al. [29] have found that daily mean saAA values of subjects suffering from the post-traumatic stress disorder (PTSD) do not differ from the control group, while the awakening samples are significantly lower for subjects with PTSD. In this study no changes in the awakening samples of saCOR or saAA have been observed between the studied time points (data not shown).

The obtained mean of 24-h HR responses and RPE values support the findings that the occupational workload was not physically demanding for the soldiers. Additionally, the HR responses were detected and calculated by the use of diaries throughout the study period during 3 typical military duties; patrolling $(\mathrm{N}=13)$, guarding $(\mathrm{N}=11)$ and logistics $(\mathrm{N}=25)$, in which the absolute and relative HR values were $78 \pm 9 \mathrm{bpm}\left(43 \pm 5 \% \mathrm{HR}_{\text {peak }}\right), 80 \pm 8(42 \pm 4)$, and $83 \pm 11(40 \pm 5)$, respectively. The observed relative values below $50 \% \mathrm{HR}_{\text {peak }}$ and $\mathrm{RPE}<10$ are classified as a very light level of physical load [21]. The results may be, at least partly, explained by the fact that both of the selected operative duties, patrolling and guarding, were performed mainly by sitting in a vehicle or standing at the military base gate, whereas logistic duties included various physical maintenance tasks such as plumbing, construction and electrical work. Moderate correlations were observed between the relative changes in mean $\mathrm{HR}^{24 \mathrm{~h}}$ and COR from MID-POST suggesting that psychological and physiological factors changed parallel.

It has been proposed that physically active lifestyle may be quantified as at least 10000 steps/day [19,20]. This 
amount was reached only in the group B during PRE. Compared to this study, even lower quantities of objectively measured PA was observed during a 4-month peacekeeping operation in Chad, where Rintamäki et al. [14] recorded fewer than 6000 steps during the one day measurement period. A study of Wyss et al. [13] showed that the average daily time spent on moderate (MET $=3-6)$ and light PA level (MET $=1.5-3$ ) was more than 3 and 4 times higher for the Swiss army recruits as compared to the initial values of this study, respectively. On the contrary, sedentary time (MET < 1.5) was nearly 6 times higher in this study. Time performing military related activities on the vigorous activity level (MET $>6$ ) during the military basic training (BT) period [13] was close to the present study. However, the most typical military duties (e.g., marching $61 \pm 23 \mathrm{~min} /$ day, demanding materials handling $33 \pm 20$ $\mathrm{min} /$ day) and running or sports activities $(36 \pm 25 \mathrm{~min} /$ day $)$ were not included in the MET values of Wyss et al. [13]. This means even a greater gap between the quantity of PA levels of MET $=3-6$ and MET $>6$ between this study and the military BT in the Swiss Armed Forces. Thus, the average volume of PA in this study was lower than the PA experienced during military BT [13]. It is noteworthy that the volume of PA in this study was significantly lower in the group A as compared to B, mainly due to the different occupational tasks. It has been proposed, on the other hand, that a higher volume of PA, in terms of physical training, is associated with higher intrinsic motivation [30] and health perception [31] during a military operation.

The overall study setting was unique in a sense that all the measurements were implemented in the operation area which may be regarded as one of the strengths of the study. To the best of our knowledge, there are no previous studies available about the changes in the quantity of objectively measured PA during military operations. On the other hand, the study setting included some limitations. One such example is the quantification of PA in respect to physical workload assessment in a military setting.
Soldiers often perform operative tasks carrying equipment and wearing body armor, which increases the strain and energy expenditure but it is not detected by an accelerometer. In addition, some activities, such as resistance training, are often performed without any significant acceleration on the hip. The additional energy cost of the above mentioned activities must be taken into consideration when evaluating the workload of soldiers based on the PA data.

However, the general finding of the rather low total volume of PA is in coherence with other results of this study, such as the low HR responses. Another limitation of the study arose from the reduced number of participants. The priority of operative duties superseded the measurements of the study, which negatively influenced the number of participants, especially during MID. Nevertheless, with the given number of subjects and based on the used methods, the obtained results offer new insights to work physiology of military occupation in a crisis management operation during operatively calm period. Due to the varying stressors affecting the soldier performance during the deployment, it must be taken into consideration that the findings of this study cannot be generalized to all crisis management operations.

\section{CONCLUSIONS}

In conclusion, the findings have demonstrated that due to the operatively calm nature of the working environment, the soldiers expressed no significant signs of physical overload during the study. This was further supported by the low quantity of PA, low HR values and slight changes in biomarkers used in this study. As such, the demanded level of physical performance (e.g., functional reserve) may not be maintained during operations lasting several months just by performing the given military duties. Future studies focusing on training interventions, aiming to maintain or improve physical performance during military operations, are warranted. 


\section{ACKNOWLEDGMENTS}

The authors appreciate Ms. Johanna Ihalainen, Ms. Mia Laakso and Ms. Moona Myllyaho for their assistance in data analysis, Mr. Pasi Ollila, Mr. Risto Puurtinen and Mrs. Aila Ollikainen for their blood and saliva analyses, and Mrs. Elina Vaara for statistical analyses.

\section{REFERENCES}

1. Erdman J, Bistrian B, Clarkson P, Dwyer J, Klein B, Lane H, et al. Nutrient composition of rations for short-term, high-intensity combat operations. Washington: The National Academies Press; 2006. p. 1-180.

2. Henning P, Park B-S, Kim J-S. Physiological decrements during sustained military operational stress. Mil Med. 2011;176(9): 991-7, https://doi.org/10.7205/MILMED-D-11-00053.

3. Sharp M, Patton J, Vogel J. A database of physically demanding tasks performed by U.S. army soldiers [Internet]. Natick: Military Performance Division, U.S. Army Research Institute of Environmental Medicine; 1998 [cited 2016 May 24]. Available from: http://www.dtic.mil/dtic/tr/fulltext/u2/a338 922.pdf.

4. Knapik J, Reynolds K, Harman E. Soldier load carriage: Historical, physiological, biomedical, and medical aspects. Mil Med. 2004;169(1):45-56, https://doi.org/10.7205/MIL MED.169.1.45.

5. Pihlainen K, Santtila M, Häkkinen K, Lindholm H, Kyröläinen $\mathrm{H}$. Cardiorespiratory responses induced by various military field tasks. Mil Med. 2014;179(2):218-24, https://doi. org/10.7205/MILMED-D-13-00299.

6. Tharion W, Lieberman H, Montain S, Young A, Baker-Fulco C, DeLany J, et al. Energy requirements of military personnel. Appetite. 2005;44:47-65, https://doi.org/10.1016/j.appet.2003.11.010.

7. Nindl B, Castellani J, Warr B, Sharp M, Henning P, Spiering B, et al. Physiological Employment Standards III: Physiological challenges and consequences encountered during international military deployments. Eur J Appl Physiol. 2013;113(11): 2655-72, https://doi.org/10.1007/s00421-013-2591-1.
8. Segerstrom S, Miller G. Psychological stress and the human immune system: A meta-analytic study of 30 years of inquiry. Psychol Bull. 2004;130:601-30, https://doi.org/10.1037/ 0033-2909.130.4.601.

9. Kyrou I, Chrousos G, Tsigos C. Stress, visceral obesity, and metabolic complications. Ann N Y Acad Sci. 2006;1083(1): 77-110, https://doi.org/10.1196/annals.1367.008.

10. Nindl B, Alemany J, Kellogg M, Rood J, Allison S, Young A, et al. Utility of circulating IGF-1 as a biomarker for assessing body composition changes in men during periods of high physical activity superimposed upon energy and sleep restriction. J Appl Physiol. 2007;103:340-6, https://doi.org/10.1152/ japplphysiol.01321.2006.

11. Friedl K, Moore R, Hoyt R, Marchitelli L, Martinez-Lopez L, Askew W. Endocrine markers of semistarvation in healthy lean men in a multistressor environment. J Appl Physiol. 2000;88:1820-30.

12. Nater U, Rohleder N. Salivary alpha-amylase as a non-invasive biomarker for the sympathetic nervous system: Current state of research. Psychoneuroendocrinology. 2009;34: 486-96, https://doi.org/10.1016/j.psyneuen.2009.01.014.

13. Wyss T, Scheffler J, Mäder U. Ambulatory physical activity in Swiss Army recruits. Int J Sports Med. 2012;33:716-22, https://doi.org/10.1055/s-0031-1295445.

14. Rintamäki H, Kyröläinen H, Santtila M, Mäntysaari M, Simonen R, Torpo H, et al. From the subarctic to the tropics: Effects of 4-month deployment on soldier's heat stress, heat strain, and physical performance. J Strength Cond Res. 2012:26(7):S45-52, https://doi.org/10.1519/JSC. 0b013e31825d817e.

15. Vähä-Ypyä H, Vasankari T, Husu P, Mänttäri A, Vuorimaa T, Suni J, et al. Validation of cut-points for evaluating the intensity of physical activity with accelerometry-based mean amplitude deviation (MAD). PLoS One. 2015;10(8): e0134813, https://doi.org/10.1371/journal.pone.0134813.

16. Borg G. Psychophysical bases of perceived exertion. Med Sci Sports Exerc. 1982;14:377-81, https://doi.org/10.1249/ 00005768-198205000-00012. 
17. Clow A, Edwards S, Owen G, Evans G, Evans P, Hucklebridge $\mathrm{F}$, et al. Post-awakening cortisol secretion during basic military training. Int J Psychophysiol. 2006;60(1):8894, https://doi.org/10.1016/j.ijpsycho.2005.05.007.

18. Nater U, Rohleder N, Schlottz W, Hhlert U, Kirschbaum C. Determinants of the diurnal course of salivary alpha-amylase. Psychoneuroendocrinology. 2007;32(4):392401, https://doi.org/10.1016/j.psyneuen.2007.02.007.

19. Tudor-Locke C, Hatano Y, Pangrazi R, Kang M. Revisiting "how many steps are enough?" Med Sci Sports Exerc. 2008;40(7):S537-43, https://doi.org/10.1249/MSS.0b013e31 $817 \mathrm{c} 7133$

20. Le Masurier G, Sidman C, Corbin C. Accumulating 10,000 steps: Does this meet current physical activity guidelines? Res Q Exerc Sport. 2003;74(4):389-94, https://doi.org/10.10 80/02701367.2003.10609109.

21. Howley E. Type of activity: Resistance, aerobic and leisure versus occupational physical activity. Med Sci Sports Exerc. 2001;33(6):S364-9, https://doi.org/10.1097/00005768-20 0106001-00005.

22. Tremblay M, Copeland J, van Helder W. Influence of exercise duration on post-exercise steroid hormone responses in trained males. Eur J Appl Physiol. 2005;94:505-13, https://doi.org/10.1007/s00421-005-1380-x.

23. Doan B, Newton R, Kraemer W, Kwon Y, Scheet T. Salivary cortisol, testosterone, and $\mathrm{T} / \mathrm{C}$ ratio responses during a 36-hole golf competition. Int J Sports Med. 2007:28:470-9, https://doi.org/10.1055/s-2006-924557.

24. Tanskanen M, Kyröläinen H, Uusitalo A, Huovinen J, Nissilä J, Kinnunen $\mathrm{H}$, et al. Serum sex hormone-binding globulin and cortisol concentrations are associated with overreaching during strenuous military training. J Strength Cond Res. 2011;25(3):787-97, https://doi.org/10.1519/JSC. 0b013e3181c1fa5d.
25. Edmonds R, Burkett B, Leicht A, McKean M. Effect of chronic training on heart rate variability, salivary $\operatorname{IgA}$ and salivary alpha-amylase in elite swimmers with a disability. PLoS One. 2015;10(6):e0127749, https://doi.org/10.1371/ journal.pone.0127749.

26. Taverniers J, de Boeck P. Force-on-Force handgun practice: An intra-individual exploration of stress effects, biomarker regulation, and behavioral changes. Hum Factors. 2014; 56(2):403-13, https://doi.org/10.1177/0018720813489148.

27. Teixeira R, Díaz M, Santos T, Bernardes J, Peixoto L, Bocanegra $\mathrm{O}$, et al. Chronic stress induces a hyporeactivity of the autonomic nervous system in response to acute mental stressor and impairs cognitive performance in business executives. PLoS One. 2015;10(3):e0119025, https://doi.org/ 10.1371/journal.pone.0119025.

28. Vineetha R, Pai K, Vengal M, Gopalakrishna K, Narayanakurup D. Usefulness of salivary alpha amylase as a biomarker of chronic stress and stress related oral mucosal changes - A pilot study. J Clin Exp Dent. 2014;6(2):e132-7, https://doi.org/10.4317/jced.51355.

29. Thoma M, Joksimovic L, Kirchbaum C, Wolf J, Rohleder N. Altered salivary alpha-amylase awakening response in Bosnian War refugees with posttraumatic stress disorder. Psychoneuroendocrinology. 2012;37:810-7, https://doi. org/10.1016/j.psyneuen.2011.09.013.

30. Dyrstad S, Miller B, Hallén J. Physical fitness, training volume and self-determined motivation in soldiers during a peacekeeping mission. Mil Med. 2007;172(2):121-7, https://doi.org/10.7205/MILMED.172.2.121.

31. Warr B, Scofield D, Spiering B, Alvar B. Influence on training frequency on fitness levels and perceived health status in deployed National Guard soldiers. J Strength Cond Res. 2013;27(2):315-22, https://doi.org/10.1519/JSC. 0b013e31827e1347.

This work is available in Open Access model and licensed under a Creative Commons Attribution-NonCommercial 3.0 Poland License - http://creativecommons.org/ licenses/by-nc/3.0/pl/deed.en. 